\title{
openheart Effects of the small molecule SIRT1 activator, SRT2104 on arterial stiffness in otherwise healthy cigarette smokers and subjects with type 2 diabetes mellitus
}

Sowmya Venkatasubramanian, ${ }^{1}$ Radzi M Noh, ${ }^{2}$ Shruti Daga, ${ }^{3}$ Jeremy $\mathrm{P}$ Langrish, ${ }^{1}$ Nicholas L Mills, ${ }^{1}$ Brian R Waterhouse, ${ }^{5}$ Ethan Hoffmann, ${ }^{4}$ Eric W Jacobson, ${ }^{4}$ Ninian N Lang, ${ }^{1}$ Brian M Frier, ${ }^{2}$ David E Newby ${ }^{1}$

To cite: Venkatasubramanian S, Noh RM, Daga S, et al. Effects of the small molecule SIRT1 activator, SRT2104 on arterial stiffness in otherwise healthy cigarette smokers and subjects with type 2 diabetes mellitus. Open Heart 2016;3:e000402. doi:10.1136/openhrt-2016000402

- Additional material is available. To view please visit the journal online (http://dx. doi.org/10.1136/openhrt2016-000402).

Received 13 January 2016 Revised 9 March 2016 Accepted 13 April 2016

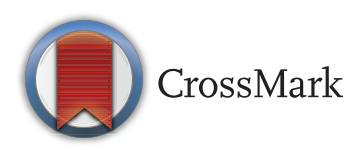

For numbered affiliations see end of article.

Correspondence to

Dr Sowmya

Venkatasubramanian;

s.venkat@ed.ac.uk

\section{ABSTRACT}

Objective: Arterial stiffness increases with age, and is associated with adverse cardiovascular outcome including increased mortality. The effect of the oral small molecule SIRT1 activator, SRT2104, on arterial stiffness was examined in otherwise healthy cigarette smokers and participants with type 2 diabetes mellitus. Methods: 24 otherwise healthy cigarette smokers and 15 people with stable type 2 diabetes were randomised in a double-blind placebo-controlled crossover trial and received 28 days of oral SRT2104 ( $2.0 \mathrm{~g} /$ day) or matched placebo. Blood pressure was measured using non-invasive oscillatory sphygmomanometry. Pulse wave analysis and velocity were measured using applanation tonometry at baseline and the end of each treatment period. Owing to the small sample size and similar trends for both groups, data for the two groups were pooled (post hoc analysis).

Results: Compared to placebo, treatment with SRT2104 was associated with a significant reduction in augmentation pressure $(p=0.0273)$ and a trend towards improvement in the augmentation index and corrected augmentation index ( $p>0.05$ for both). However, no changes were observed in pulse wave velocity and time to wave reflection ( $p>0.05$ ). Systolic and diastolic blood pressures remained unchanged throughout the study. Treatment by cohort interaction was not significant for any of the pulse wave parameters, suggesting that the response to SRT2104 in otherwise healthy smokers and people with diabetes was consistent.

Conclusions: SRT2104 may improve measures of arterial stiffness in otherwise healthy cigarette smokers and in participants with type 2 diabetes. Definitive conclusions are not possible given the small sample size and exploratory nature of this analysis.

Trial registration number: NCT01031108.

\section{INTRODUCTION}

The enzyme sirtuin (silent mating-type information regulation 2 homologue) 1 (SIRT1)

\section{KEY QUESTIONS}

What is already known about this subject?

- Among the seven known sirtuins, SIRT1 has been identified as the most critical modulator of vascular function. Animal and laboratory studies have amply demonstrated its prominent role in the regulation of vascular homeostasis and diseases. However, little is known about their direct vascular effects in man.

What does this study add?

- The present study has provided evidence that suggests treatment with the oral SIRT1 activator, SRT2104, may lead to an improvement in measures of arterial compliance in otherwise healthy cigarette smokers and people with type 2 diabetes. The exact mechanism of this improved arterial compliance and the effects of prolonged treatment with SRT2104 on vascular health remain to be elucidated.

How might this impact on clinical practice?

- Given that aortic stiffness and endothelial function are key factors in predicting cardiovascular outcomes, identification of novel pharmacological means of improving these predictive parameters is important and highly relevant in populations with known cardiovascular risk factors.

belongs to the sirtuin family of nicotinamide adenine dinucleotide-dependent histone deacetylases and is highly expressed in the vascular endothelium. ${ }^{1}$ In addition to other characteristics, its activation is associated with improved endothelial function ${ }^{2}$ and inhibition of atherogenesis. ${ }^{3}$ Particular interest has been focused on the potential of therapeutic SIRT1 activators to act as anti-ageing agents.

Arterial stiffness rises with age and is recognised to be an independent predictor of 
cardiovascular risk. ${ }^{4}$ In particular, elevations in pulse pressure and aortic stiffness are associated with increased risk of coronary events and overall mortality. ${ }^{5}$ Indeed, central aortic stiffness is associated with the presence of coronary atherosclerosis and ischaemic heart disease. ${ }^{6}$

Cigarette smoking and diabetes mellitus are significant risk factors for the development of cardiovascular disease. A wealth of data has established a strong correlation between diabetes and cigarette smoke exposure with increased aortic stiffness, endothelial dysfunction and cardiovascular risk. ${ }^{7-10}$ New pharmacological strategies that improve arterial compliance would therefore be highly relevant to these groups at increased cardiovascular risk.

The aims of the present study were to assess the effect of the oral SIRT1 activator, SRT2104, on measures of arterial compliance in otherwise healthy cigarette smokers and patients with type 2 diabetes. It was hypothesised that SIRT1 activation in these 'at risk' groups could lead to an improvement in arterial compliance and therefore reduce their cardiovascular risk.

\section{METHODS}

The study was approved by the Berkshire Research Ethics Committee, received Clinical Trial Authorisation from the Medicines and Healthcare products Regulatory Agency (MHRA, UK), and was conducted at the MHRA phase I accredited Wellcome Trust Clinical Research Facility at the Royal Infirmary of Edinburgh, UK between June 2010 and September 2011 (EudraCT \#: 2009-016765-28; Clinical trials identifier: NCT01031108). Written informed consent was obtained from each volunteer and the study was carried out in accordance with the declaration of Helsinki.

\section{Study participants}

Twenty-four otherwise healthy cigarette smokers and 15 participants with stable type 2 diabetes, aged between 18 and 70 years, were eligible for the study. Healthy cigarette smokers were required to have smoked $\geq 10$ cigarettes daily for at least 1 year. Participants with type 2 diabetes were non-smokers and were selected on the basis of having a diagnosis of type 2 diabetes mellitus for at least 6 months prior to inclusion in the study, with no change in medications having been made for at least the preceding 3 months, a fasting blood glucose $\leq 13.9 \mathrm{mmol} / \mathrm{L}(250 \mathrm{mg} / \mathrm{dL})$ and diabetes control and complications trial-aligned $\mathrm{HbAlc}<9 \%(75 \mathrm{mmol} / \mathrm{mol})$ on screening. Exclusion criteria included the presence of significant comorbidities, chronic illness, renal or liver impairment, history of gastrointestinal diseases or previous surgical procedures that would influence drug absorption, history of alcoholism, history of neoplastic disease within the last 5 years, a positive urinary test for recreational drugs, pregnancy and participation in other clinical trials or blood donation within the last
3 months. Patients with type 2 diabetes mellitus on ACE inhibitors, antiplatelet or anticoagulant therapies were excluded from the study. Tests for pregnancy (serum human chorionic gonadotropin (HCG) concentrations at screening and urinary HCG concentrations at study visits) were conducted on all female participants of childbearing potential.

\section{Study design}

This was a prospective double-blind randomised placebo-controlled cross-over study. Participants were randomised to receive $2.0 \mathrm{~g}$ daily of oral SRT2104 or matched placebo (Sirtris, a GSK company, Massachusetts, USA) for a 28-day period, followed by cross-over to the alternate study arm for a further 28 days, giving a total dosing duration of 56 days. An end of study visit was conducted at day 70 with a telephone call follow-up on day 86. Measures of arterial stiffness were undertaken prior to and at the end of each 28-day trial period. Figure 1 outlines participant enrolment, intervention allocation, follow-up and data analysis for both groups.

All studies were performed in a quiet temperature controlled $\left(22-25^{\circ} \mathrm{C}\right)$ room. Participants were fasted and asked to refrain from smoking for $10 \mathrm{~h}$, and abstain from caffeine and alcohol for $24 \mathrm{~h}$ prior to assessment. Participants remained supine for at least $30 \mathrm{~min}$ before any recordings were started. Systolic and diastolic blood pressures were recorded using a non-invasive oscillatory sphygmomanometer (Omron705 IT, Omron Healthcare Europe, the Netherlands).

Pulse wave analysis of the radial artery was performed at the wrist using micromanometer applanation tonometry (Millar Instruments, Texas, USA) and the SphygmoCor system (AtCor Medical, Sydney, Australia) in accordance with the manufacturer's recommendations. Briefly, pulse wave analysis derives an aortic pulse pressure waveform from the radial artery wave via a mathematical transfer function. The arterial pressure waveform is a composite of the forward pressure wave created by ventricular contraction and a reflected wave generated by peripheral vascular resistance. ${ }^{11}$ The augmentation pressure is the pressure difference between the second and first systolic peaks. The augmentation index, augmentation pressure as a percentage of the pulse pressure, is a measure of systemic arterial stiffness and wave reflection. Corrected augmentation index represents the augmentation index corrected for heart rate. $^{12}$ The time to wave reflection declines with increasing arterial stiffness, and provides a surrogate measure of aortic pulse wave velocity. ${ }^{13}$ At least three independent waveform analyses were obtained from each participant, with measurements only accepted on meeting SphygmoCor quality control criteria. Pulse wave velocity was calculated by measuring the time for the pulse wave to travel between the carotid and femoral arteries. The operator performing the analysis was kept constant for each participant throughout the study. 


\section{A}

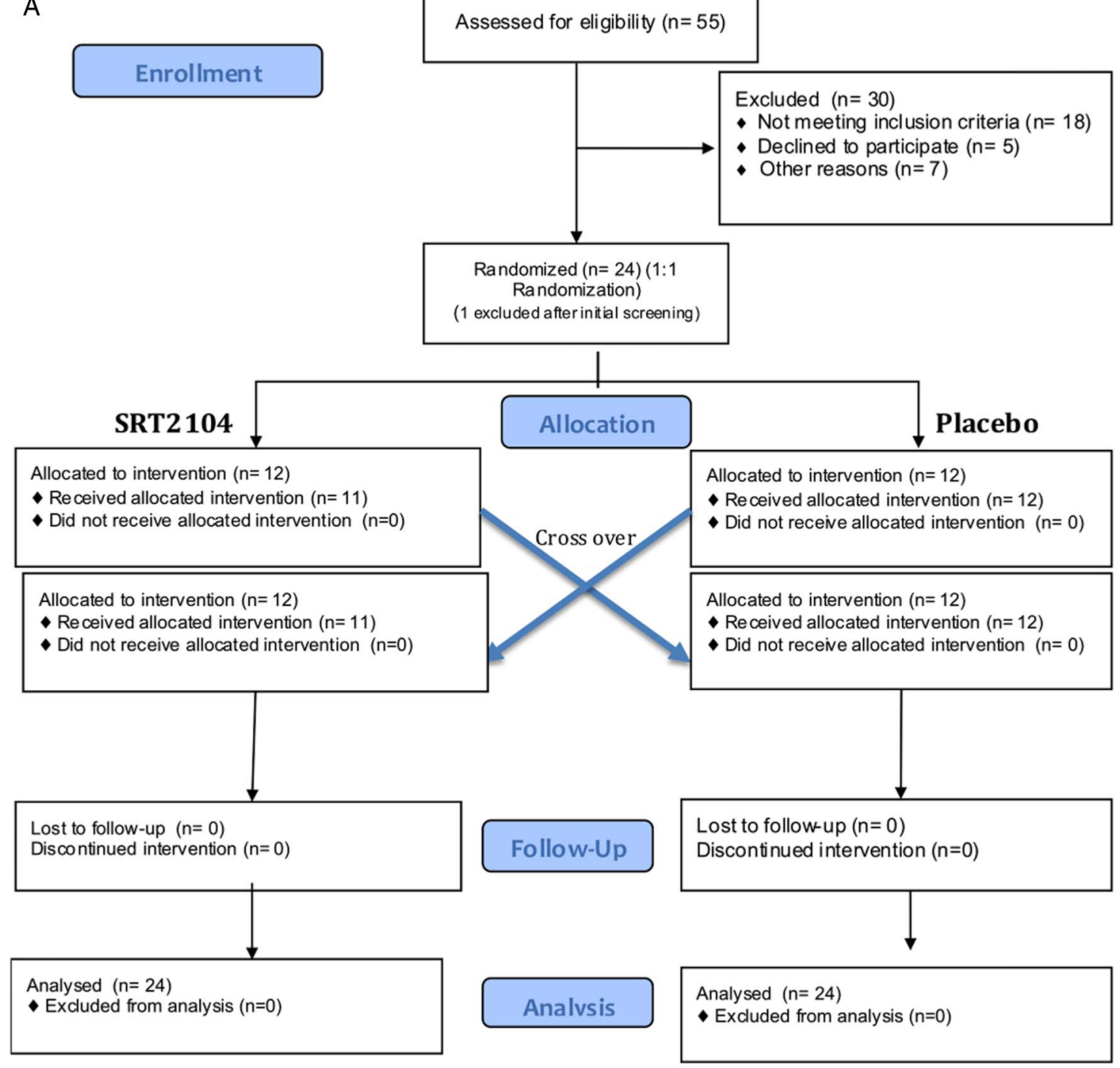

Figure 1 Consolidated Standards of Reporting Trials flow diagram representing participant enrolment, intervention allocation, follow-up and data analysis. (A) Recruitment of otherwise healthy cigarette smokers; (B) participants with type 2 diabetes mellitus.

\section{Blood sampling}

Venous blood samples were collected at fortnightly intervals to measure haematological and biochemical analytes including full blood count, coagulation profile, liver and renal function, creatine kinase, lactate dehydrogenase and lipid profile. Analyses were conducted by the regional clinical haematology and biochemistry reference laboratories using an automated haematology analyser (XE2100, Sysmex Corporation (Japan) and ACL TOP, Instrumentation Laboratory), an automated chemistry analyser using colorimetric, kinetic and enzymatic ultraviolet and colour assays (AU2700/AU640 analysers, Beckman and Coulter), ion selective electrodes (sodium, potassium and chloride assays) and two point and multiple point rate assays (Ortho Clinical Vitros 250 analyser, USA).

\section{Data analysis and statistics}

Data were analysed, where appropriate, using repeated measure analysis of covariance on the change from baseline for all parameters. Initially, analyses were conducted separately on cohorts. As a result of the small sample size and similar trends for the two cohorts, these data were pooled post hoc. Treatment differences were investigated in a model adjusting for baseline, period, treatment by period and treatment by cohort using SAS for UNIX (V.9.1.3 or higher) (SAS Institute, Cary, North Carolina, USA). Unless stated otherwise, values are expressed as mean \pm SD. Tests for treatment effect were two-sided with a significance level of 0.05 .

\section{RESULTS}

\section{Baseline characteristics}

Participants in the study had a mean age of $45 \pm 15$ years and were predominantly male $(68 \%)$. Participants in the type 2 diabetes cohort were older (mean age $58 \pm 8$ years) when compared with the participants in the otherwise healthy smokers group (mean age $38 \pm 13$ years). All participants were normotensive with comparable systolic 


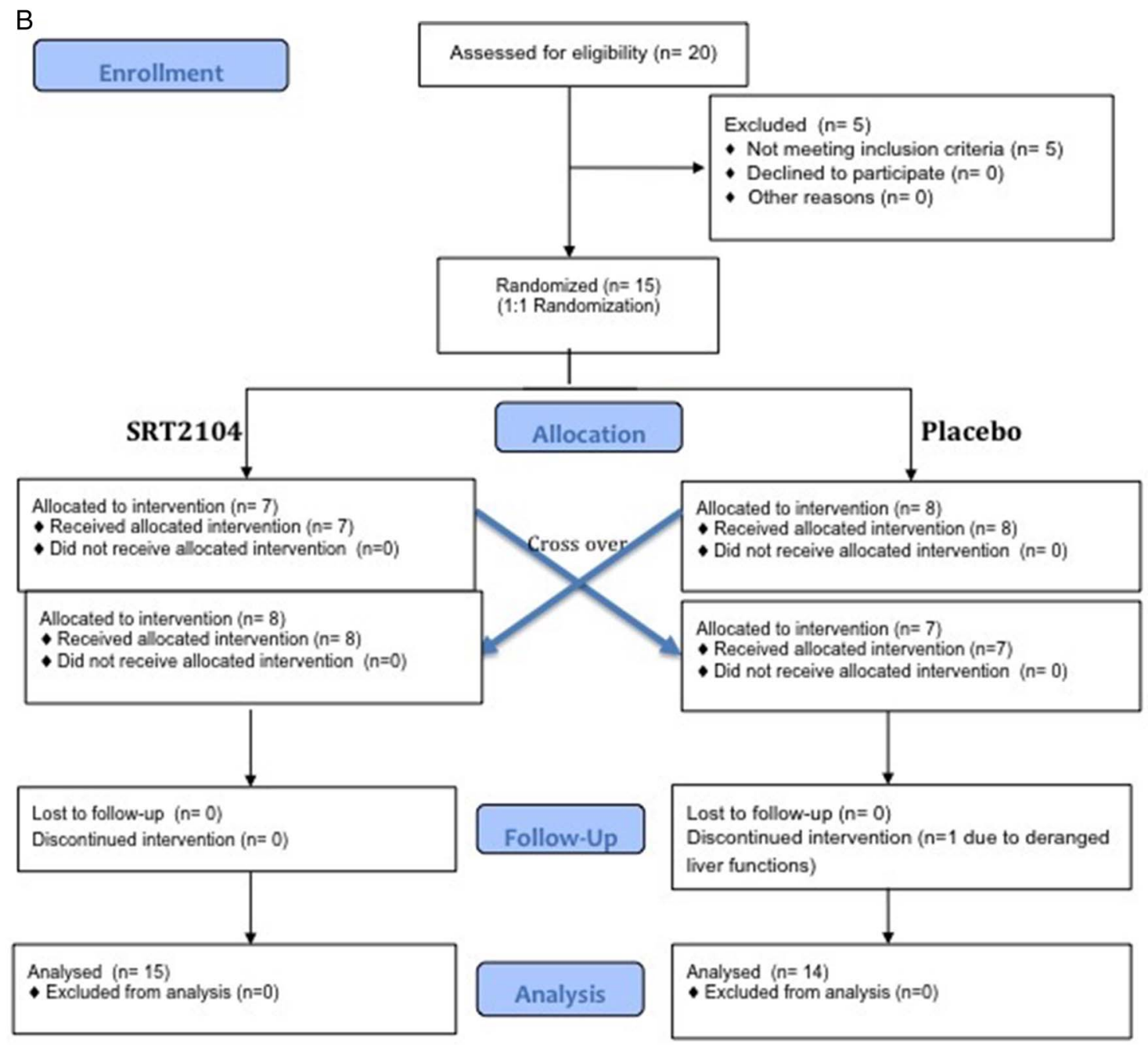

Figure 1 Continued

and diastolic blood pressures at baseline (table 1). No clinically significant changes in haematological or biochemical analytes occurred throughout the study. Biochemical measures of renal function (serum urea, creatinine and electrolytes) were within normal limits at baseline and remained unchanged with placebo and treatment with SRT2104 in both subgroups (table 2).

\section{Blood pressure}

Resting systolic and diastolic blood pressures remained unchanged throughout the study with no significant differences between treatment and placebo treatment periods.

\section{Pulse wave analysis and velocity}

In a combined analysis of otherwise healthy cigarette smokers and participants with type 2 diabetes, a reduction in the augmentation pressure was observed in participants receiving SRT2104 compared with placebo (mean change from baseline: SRT2104-1.60 (5.304) vs placebo-0.06 (4.205); $\mathrm{p}=0.0273$ ) and a trend towards improvement in the augmentation index (mean change from baseline in AIx: placebo-0.64 (8.361) vs SRT2104 -3.47 (9.728); $\mathrm{p}=0.0813)$ and the corrected augmentation index (mean change from baseline AIx75: placebo $-2.2-(7.453)$ vs SRT2104-4.84 (9.299); $\mathrm{p}=0.0747)$ (figure 2A). Pulse wave velocity and time to wave reflection remained unchanged between placebo and treatment arms ( $>0.05$ for both parameters; figure 2B). The effects of SRT2104 administration on measures of arterial compliance were consistent across the two cohorts. For example, in the SRT2104 arm, mean augmentation index at $75 \mathrm{bpm}$ was reduced for healthy smokers and participants with type 2 diabetes $(-4.97$ vs -4.63 , respectively). Measures of arterial compliance and stiffness for the individual cohorts have been presented in the online supplementary table S1. A statistical interaction between cohort and treatment was not observed ( $p>0.05$ for all variables tested).

\section{Tolerability and safety}

Participants in both study groups (healthy cigarette smokers and patients with type 2 diabetes) tolerated the study medication well. There were no meaningful 
Table 1 Baseline characteristics of participants who were otherwise healthy cigarette smokers or who had type 2 diabetes mellitus

\begin{tabular}{|c|c|c|}
\hline & $\begin{array}{l}\text { Otherwise healthy cigarette } \\
\text { smokers }(n=24)\end{array}$ & $\begin{array}{l}\text { People with type } 2 \\
\text { diabetes }(n=15)\end{array}$ \\
\hline Mean age (years) & $38 \pm 13$ & $58 \pm 8$ \\
\hline \multicolumn{3}{|l|}{ Sex } \\
\hline Male & $14(58)$ & $13(87)$ \\
\hline Female & $10(42)$ & $2(13)$ \\
\hline \multicolumn{3}{|l|}{ Baseline blood pressure $(\mathrm{mm} \mathrm{Hg})$} \\
\hline Systolic & $129 \pm 6$ & $133 \pm 7$ \\
\hline Diastolic & $77 \pm 2$ & $80 \pm 3$ \\
\hline Heart rate $(\mathrm{bpm})$ & $68 \pm 1$ & $77 \pm 5$ \\
\hline Body mass index $\left(\mathrm{kg} / \mathrm{m}^{2}\right)$ & $25 \pm 4$ & $30 \pm 4$ \\
\hline \multicolumn{3}{|l|}{ Smoking history } \\
\hline Number of cigarettes/day & $17 \pm 6$ & - \\
\hline Number of pack years & 16 & - \\
\hline Urinary cotinine concentration $(\mathrm{ng} / \mathrm{mL})$ & $1352 \pm 950$ & - \\
\hline \multicolumn{3}{|l|}{ Glycaemic profile } \\
\hline Baseline blood glucose (mg/dL) & $85 \pm 0$ & $144 \pm 2$ \\
\hline HbA1c (\%) & - & $7.4 \pm 0.8$ \\
\hline \multicolumn{3}{|l|}{ Concomitant medications } \\
\hline Antiplatelet agents & - & $5(33 \%)$ \\
\hline Antihypertensive agents & - & $3(20 \%)$ \\
\hline ARB & - & $2(13 \%)$ \\
\hline Diuretics & - & $10(67 \%)$ \\
\hline Lipid lowering agents & - & $13(86 \%)$ \\
\hline Hypolycaemic agents & - & $4(27 \%)$ \\
\hline Biguanide & - & $2(13 \%)$ \\
\hline Sulfonamide & - & $1(6 \%)$ \\
\hline Thiazolidine & - & $2(13 \%)$ \\
\hline \multicolumn{3}{|l|}{ Insulin } \\
\hline Others & & \\
\hline
\end{tabular}

differences in the number of adverse events between active treatment and placebo. All reported adverse events were mild in intensity and resolved without any intervention or sequelae (table 3). Headaches occurred with nearly equal frequency in the treatment (SRT2104) group in both cohorts. Participants with type 2 diabetes appeared to have more frequent gastrointestinal disturbances, such as diarrhoea and nausea in comparison with healthy smokers. Elevated liver enzymes (alanine transaminase) resulted in withdrawal of one participant in the placebo period (day 36) of the diabetes group. There was only one reported serious adverse event in the study (SRT2104 arm of healthy cigarette smokers) of traumatic facial bone fracture that was considered unrelated to SRT2104.

\section{DISCUSSION}

This randomised double-blinded cross-over study demonstrated for the first time that the oral SIRT1 activator, SRT2104, may improve arterial compliance in otherwise healthy cigarette smokers and in people with type 2 diabetes, without affecting resting measures of blood pressure.
The assessment of arterial stiffness is increasingly being used in clinical practice as an independent measure of cardiovascular risk, including those in highrisk groups. ${ }^{14}$ Ageing is associated with an increase in the stiffness of large elastic arteries induced by structural alterations in the vascular media such as an increase in collagen and a decrease in elastin content. ${ }^{15}$ This process of biological ageing is accelerated in the presence of conditions such as diabetes mellitus and hypertension. Semba et $a l^{16}$ and Hofmann et $a l^{17}$ have demonstrated an association between the presence of advanced glycation end products and increased arterial stiffness. Indeed, vascular change induced by cigarette smoke is considered to be a model of accelerated vascular ageing. The relationship between tobacco exposure, ${ }^{9} 10^{18}$ diabetes $^{7} 81920$ and increased arterial stiffness is well established.

Calorie restriction can attenuate age-related arterial stiffness in animal models through reduced oxidative stress and altered endothelial nitric oxide bioavailability. ${ }^{15}$ Indeed, calorie restriction can extend lifespan in lower organisms and mammals, and improves several metabolic and inflammatory parameters. ${ }^{21-26}$ SIRT1 has been implicated as an important mediator of lifespan 
Table 2 Changes in biochemical measures of renal function in otherwise healthy cigarette smokers and participants with type 2 diabetes mellitus administered placebo and SRT2104

\begin{tabular}{|c|c|c|c|c|c|c|c|c|}
\hline & \multicolumn{4}{|c|}{$\begin{array}{l}\text { Otherwise healthy cigarette smokers } \\
(n=24)\end{array}$} & \multicolumn{4}{|c|}{ Participants with type 2 diabetes $(n=15)$} \\
\hline & \multicolumn{2}{|c|}{$\begin{array}{l}\text { Treatment period } \\
\text { 1: placebo }(n=13)\end{array}$} & \multicolumn{2}{|c|}{$\begin{array}{l}\text { Treatment period } \\
\text { 1: SRT2104 }(n=11)\end{array}$} & \multicolumn{2}{|c|}{$\begin{array}{l}\text { Treatment period } \\
\text { 1: placebo }(n=8)\end{array}$} & \multicolumn{2}{|c|}{$\begin{array}{l}\text { Treatment period } \\
\text { 1: SRT2104 }(n=7)\end{array}$} \\
\hline & Day 1 & Day 28 & Day 1 & Day 28 & Day 1 & Day 28 & Day 1 & Day 28 \\
\hline Serum urea (mg/dL) & $17 \pm 3$ & $14 \pm 3$ & $11 \pm 3$ & $14 \pm 3$ & $17 \pm 3$ & $17 \pm 3$ & $17 \pm 6$ & $14 \pm 3$ \\
\hline Serum creatinine $(\mathrm{mg} / \mathrm{dL})$ & $0.8 \pm 0.1$ & $0.8 \pm 0.1$ & $0.7 \pm 0.1$ & $0.8 \pm 0.1$ & $0.8 \pm 0.1$ & $0.8 \pm 0.1$ & $0.9 \pm 0.1$ & $0.9 \pm 0.1$ \\
\hline \multicolumn{9}{|l|}{ Electrolytes } \\
\hline Sodium (mmol/L) & $140 \pm 2$ & $140 \pm 2$ & $140 \pm 2$ & $140 \pm 1$ & $139 \pm 1$ & $139 \pm 3$ & $138 \pm 2$ & $139 \pm 3$ \\
\hline Potassium (mmol/L) & $4.0 \pm 0.4$ & $4.0 \pm 0.4$ & $4.0 \pm 0.4$ & $4.0 \pm 0.2$ & $4.0 \pm 0.3$ & $4.0 \pm 0.3$ & $4.0 \pm 0.2$ & $4.0 \pm 0.4$ \\
\hline Chloride (mmol/L) & $109 \pm 3$ & $107 \pm 3$ & $108 \pm 3$ & $107 \pm 2$ & $104 \pm 4$ & $104 \pm 3$ & $103 \pm 2$ & $104 \pm 2$ \\
\hline
\end{tabular}

extension mediated by calorie restriction. ${ }^{27-29}$ The current hypothesis, therefore, was that activation of SIRT1 may inhibit this process of vascular ageing and be associated with improvements in arterial stiffness.
No studies have examined the direct effect of SIRT1 activation on measures of arterial compliance. Botden et $a l^{30}$ were unable to demonstrate an improvement in augmentation index or central or peripheral blood
A Augmentation Index

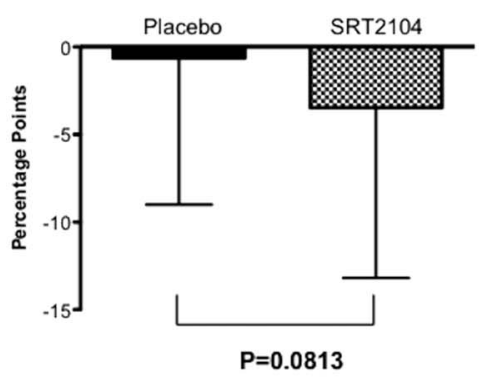

Augmentation Pressure

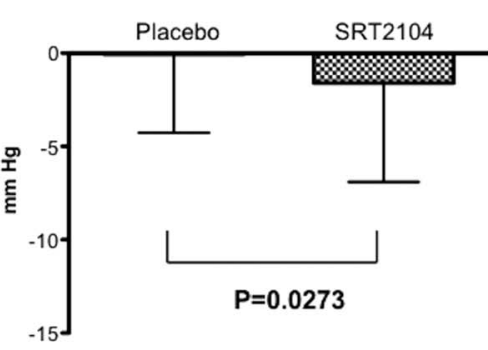

C

\section{Corrected Augmentation Index (Alx75)}
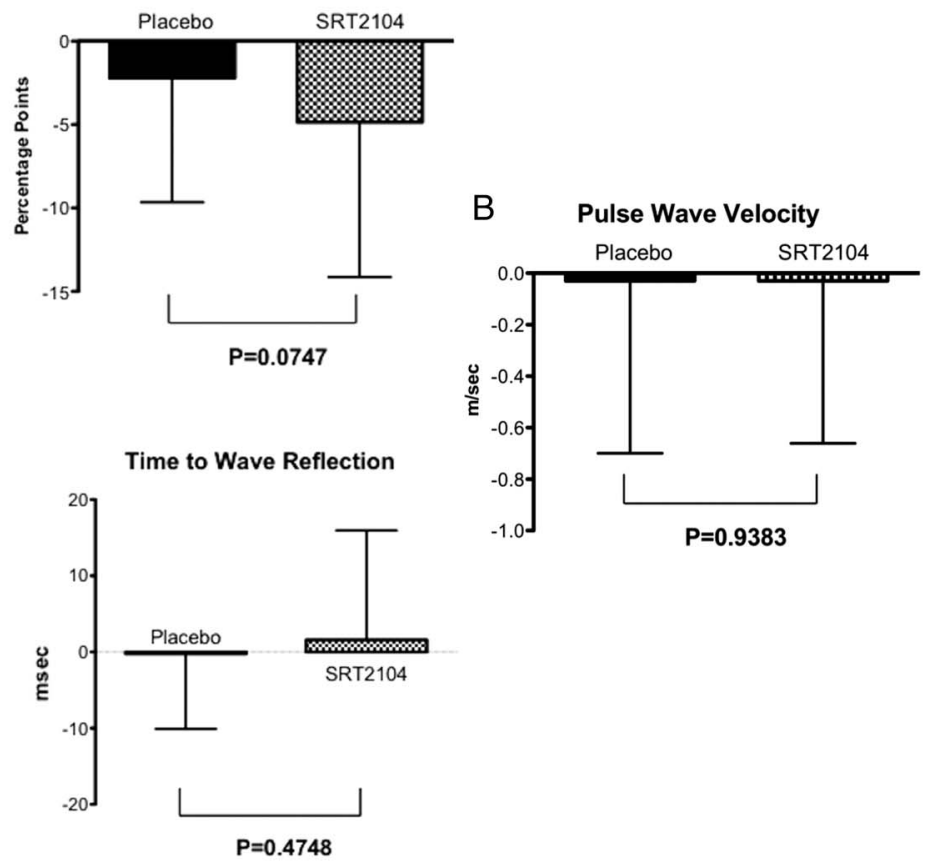

Figure 2 Effect of treatment with SRT2104 on measures of arterial compliance in otherwise healthy cigarette smokers and participants with type 2 diabetes mellitus-change from baseline. (A) Pulse wave analysis-augmentation index, corrected augmentation index, augmentation pressure and time to wave reflection. (B) pulse wave velocity. Solid column: placebo; checked column: SRT2104. (C) baseline parameters of measures of arterial compliance-combined data. 
Table 3 Summary of treatment emergent adverse events occurring in two or more participants in OHS and participants with T2DM

\begin{tabular}{|c|c|c|c|c|c|}
\hline \multirow[b]{3}{*}{ System organ class } & \multirow[b]{3}{*}{ Adverse event } & \multicolumn{4}{|c|}{ Number of events } \\
\hline & & \multicolumn{2}{|c|}{ OHS } & \multicolumn{2}{|l|}{ T2DM } \\
\hline & & $\begin{array}{l}\text { Placebo } \\
(n=24)\end{array}$ & $\begin{array}{l}\text { SRT2104 } \\
(n=24)\end{array}$ & $\begin{array}{l}\text { Placebo } \\
(n=14)\end{array}$ & $\begin{array}{l}\text { SRT2104 } \\
n=15)\end{array}$ \\
\hline Any event & & 18 & 18 & 11 & 14 \\
\hline \multirow[t]{5}{*}{ Nervous system disorders } & Any event & $6(25 \%)$ & $11(46 \%)$ & $1(7 \%)$ & 7 (47\%) \\
\hline & Headache & 4 & 6 & 1 & 5 \\
\hline & Paraesthesia & 0 & 2 & 0 & 1 \\
\hline & Hypoaesthesia & 1 & 2 & 0 & 0 \\
\hline & Presyncope & 1 & 1 & 0 & 0 \\
\hline \multirow{3}{*}{$\begin{array}{l}\text { Respiratory, thoracic and } \\
\text { mediastinal disorders }\end{array}$} & Any event & $1(4 \%)$ & $3(13 \%)$ & 0 & $3(20 \%)$ \\
\hline & Oropharyngeal pain & 1 & 2 & 0 & 0 \\
\hline & Rhinorrhoea & 0 & 1 & 0 & 1 \\
\hline \multirow[t]{5}{*}{ Gastrointestinal disorders } & Any event & $3(13 \%)$ & $1(4 \%)$ & $4(29 \%)$ & $8(53 \%)$ \\
\hline & Diarrhoea & 0 & 0 & 2 & 4 \\
\hline & Nausea & 0 & 0 & 1 & 2 \\
\hline & Abdominal pain upper & 1 & 0 & 0 & 1 \\
\hline & Dyspepsia & 0 & 0 & 0 & 2 \\
\hline \multirow{4}{*}{$\begin{array}{l}\text { Reproductive system and breast } \\
\text { disorders } \\
\text { Musculoskeletal and connective } \\
\text { tissue disorders }\end{array}$} & Any event & $3(13 \%)$ & $1(4 \%)$ & 0 & 0 \\
\hline & Dysmenorrhea & 3 & 1 & 0 & 0 \\
\hline & Any event & $4(17 \%)$ & $1(4 \%)$ & 0 & $2(13 \%)$ \\
\hline & Back pain & 2 & 0 & 0 & 0 \\
\hline \multirow[t]{4}{*}{ Investigational } & Any event & $2(8 \%)$ & $1(4 \%)$ & $1(7 \%)$ & $1(7)$ \\
\hline & Blood bilirubin increased & 1 & 1 & 0 & 0 \\
\hline & $\begin{array}{l}\text { Alanine amino transferase } \\
\text { increased }\end{array}$ & 0 & 0 & 1 & 0 \\
\hline & $\begin{array}{l}\text { Abnormal liver function } \\
\text { test }\end{array}$ & 0 & 0 & 0 & 1 \\
\hline General disorders and & Any event & $4(17 \%)$ & $4(17 \%)$ & $2(14 \%)$ & $3(20 \%)$ \\
\hline \multirow[t]{2}{*}{ administration site conditions } & Influenza like illness & 1 & 0 & 0 & 1 \\
\hline & Fatigue & 1 & 0 & 1 & 1 \\
\hline \multirow[t]{4}{*}{ Infections and infestations } & Any event & $3(13 \%)$ & $5(21 \%)$ & $3(21 \%)$ & $1(7 \%)$ \\
\hline & Nasopharyngitis & 0 & 1 & 3 & 0 \\
\hline & Rhinitis & 2 & 2 & 0 & 0 \\
\hline & $\begin{array}{l}\text { Upper respiratory tract } \\
\text { infection }\end{array}$ & 1 & 0 & 0 & 1 \\
\hline \multirow{3}{*}{$\begin{array}{l}\text { Injury, poisoning and procedural } \\
\text { complications }\end{array}$} & Any event & $4(17 \%)$ & $2(8 \%)$ & $3(21 \%)$ & $1(7 \%)$ \\
\hline & Contusion & 1 & 0 & 1 & 0 \\
\hline & Excoriation & 1 & 1 & 0 & 0 \\
\hline \multirow[t]{2}{*}{ Skin and subcutaneous tissue } & Any event & $1(4 \%)$ & 0 & $1(7 \%)$ & $3(20 \%)$ \\
\hline & Pruritus & 0 & 0 & 0 & 2 \\
\hline \multirow[t]{2}{*}{ Metabolism and nutrition disorders } & Any event & 0 & $1(4 \%)$ & $2(14 \%)$ & $2(13 \%)$ \\
\hline & Hypoglycaemia & 0 & 0 & 1 & 2 \\
\hline \multirow[t]{2}{*}{ Vascular disorders } & Any event & 0 & $1(4 \%)$ & 0 & $2(13 \%)$ \\
\hline & Flushing & 0 & 0 & 0 & 2 \\
\hline
\end{tabular}

OHS, otherwise healthy cigarette smokers; T2DM, type 2 diabetes mellitus.

pressure following treatment with red wine polyphenols. In the present study, a 28-day period of treatment with the oral SIRT1 activator SRT2104 was associated with a reduction in augmentation pressure and trends towards improvement in augmentation index and corrected augmentation index. Augmentation pressure and index are measures of arterial compliance and wave reflection from small to medium sized arteries. As such, they can be influenced by endothelial function and a number of other dynamic and functional factors, such as heart rate and peripheral circulatory tone. ${ }^{7}{ }^{14}$ Preclinical studies have demonstrated improved vascular function with SIRT1 activation, ${ }^{2}{ }^{31-33}$ and this may explain our observations of improvement in dynamic measures of arterial stiffness following short-term administration of SRT2104.

Pulse wave velocity is a more direct measure of arterial stiffness that is determined by the structural and physical composition of the arterial wall. ${ }^{8}$ Changes in pulse wave velocity are therefore more gradual and less dependent on the function of small to medium sized arteries. In 
the present study, a change in pulse wave velocity was not observed with SRT2104 administration. This is perhaps not surprising given the short-time period of exposure to SRT2104 (28 days) and the brief period of observation. An improvement in pulse wave velocity might be anticipated with a longer period of treatment with SRT2104, to allow more favourable structural changes in the larger arterial tree.

\section{STUDY LIMITATIONS}

Some limitations of this trial should be considered. Although favourable trends in parameters of arterial compliance were observed, some did not achieve statistical significance. This may partly be attributed to the trial being designed specifically to examine the acute effects of treatment with SRT2104. A longer period of treatment may be required for benefits to emerge on variables such as pulse wave velocity that involve structural changes in the arterial wall. Moreover, the sample sizes of the two groups examined were small. Two disparate populations were studied in this trial, in whom the mechanisms of vascular dysfunction may be very different. However, the direction of beneficial effects on treatment with SRT2104 was similar between the two groups, providing reassurance of a consistency of effect and allowing the post hoc presentation of the results pooled across the two groups.

\section{Conclusion}

The present study has provided evidence that suggests treatment with the oral SIRT1 activator, SRT2104, may lead to an improvement in measures of arterial compliance in otherwise healthy cigarette smokers and people with type 2 diabetes. The exact mechanism of this improved arterial compliance and the effects of prolonged treatment with SRT2104 on vascular health remain to be elucidated. Given that aortic stiffness and endothelial function are key factors in predicting cardiovascular outcomes, identification of novel pharmacological means of improving these predictive parameters is important and highly relevant in populations with known cardiovascular risk factors.

\author{
Author affiliations \\ ${ }^{1}$ Centre for Cardiovascular Science, University of Edinburgh, Edinburgh, UK \\ ${ }^{2}$ Department of Diabetes, Royal Infirmary, Edinburgh, UK \\ ${ }^{3}$ GlaxoSmithKline, London, UK \\ ${ }^{4}$ Sirtris, a GSK Company, Cambridge, Massachusetts, USA \\ ${ }^{5}$ GlaxoSmithKline, Philadelphia, Pennsylvania, USA
}

Acknowledgements The authors would like to thank staff of the Wellcome Trust Clinical Research Facility in Edinburgh for their assistance with this study. The authors would also like to thank Alison Hinds and Michelle Rostant-Belle from the Scottish Primary Care Research Network for their help with recruitment and to the colleagues at Sirtris, a GSK company, Cambridge, Massachusetts, USA for their support throughout the study.

Contributors SD, JPL, NLM, BRW, BMF and DEN were involved in planning of the trial, data analysis and review and revision of manuscript. SV, RMN, NNL and DEN were involved in the conduct of the trial, data analysis and preparation and review of the manuscript. BW, EH, EWJ and DEN were involved in planning of the trial, data analysis and statistics and review of the manuscript.

Funding Funding for this study was provided by Sirtris, a GlaxoSmithKline company Cambridge, Massachusetts, USA. Sirtris also supplied the study drug SRT2104 and its matching placebo.

Competing interests SV, RMN, JPL, NLM, NNL, BMF and DEN-no disclosures; SD is currently an employee of GlaxoSmithKline and owns GSK stock, UK; EH and EWJ are employees of Sirtris Pharmaceuticals, Massachusetts, USA and own stock; BRW is an employee of GlaxoSmithKline, Pennsylvania, USA and owns stock.

Patient consent Obtained.

Ethics approval Berkshire Research Ethics Committee.

Provenance and peer review Not commissioned; externally peer reviewed.

Data sharing statement No additional data are available.

Open Access This is an Open Access article distributed in accordance with the terms of the Creative Commons Attribution (CC BY 4.0) license, which permits others to distribute, remix, adapt and build upon this work, for commercial use, provided the original work is properly cited. See: http:// creativecommons.org/licenses/by/4.0/

\section{REFERENCES}

1. Edirisinghe I, Rahman I. Cigarette smoke-mediated oxidative stress, shear stress, and endothelial dysfunction: role of VEGFR2. Ann N Y Acad Sci 2010;1203:66-72.

2. Mattagajasingh I, Kim CS, Naqvi A, et al. SIRT1 promotes endothelium-dependent vascular relaxation by activating endothelia nitric oxide synthase. Proc Natl Acad Sci USA 2007;104: 14855-60.

3. Stein S, Lohmann C, Schäfer N, et al. SIRT1 decreases Lox-1-mediated foam cell formation in atherogenesis. Eur Heart $J$ 2010;31:2301-9.

4. Cockcroft JR, Wilkinson IB. Arterial stiffness and pulse contour analysis: an age old concept revisited. Clin Sci 2002;103:379-80.

5. Vlachopoulos C, Aznaouridis K, Stefanadis C. Prediction of cardiovascular events and all-cause mortality with arterial stiffness: a systematic review and meta-analysis. J Am Coll Cardiol 2010;55:1318-27.

6. McLeod AL, Uren NG, Wilkinson IB, et al. Non-invasive measures of pulse wave velocity correlate with coronary arterial plaque load in humans. J Hypertens 2004;22:363-8.

7. Stehouwer CDA, Henry RMA, Ferreira I. Arterial stiffness in diabetes and the metabolic syndrome: a pathway to cardiovascular disease. Diabetologia 2008;51:527-39

8. Roos CJ, Djaberi R, Schuijf JD, et al. Relationship between vascula stiffness and stress myocardial perfusion imaging in asymptomatic patients with diabetes. Eur J Nucl Med Mol Imaging 2011;38:2050-7.

9. Rehill N, Beck CR, Yeo KR, et al. The effect of chronic tobacco smoking on arterial stiffness. Br J Clin Pharmacol 2006;61:767-73.

10. Binder S, Navratil K, Halek J. Chronic smoking and its effect on arterial stiffness. Biomed Pap Med Fac Univ Palacky Olomouc Czech Repub 2008;152:299-302.

11. Lundbäck M, Mills NL, Lucking A, et al. Experimental exposure to diesel exhaust increases arterial stiffness in man. Part Fibre Toxicol 2009;6:7.

12. Wilkinson IB, MacCallum $\mathrm{H}$, Flint $\mathrm{L}$, et al. The influence of heart rate on augmentation index and central arterial pressure in humans. $J$ Physiol (Lond) 2000;525(Pt 1):263-70.

13. Mills NL, Miller JJ, Anand A, et al. Increased arterial stiffness in patients with chronic obstructive pulmonary disease: a mechanism for increased cardiovascular risk. Thorax 2008;63:306-11.

14. Laurent S, Cockcroft J, Van Bortel L, et al. Expert consensus document on arterial stiffness: methodological issues and clinical applications. Eur Heart J 2006;27:2588-605.

15. Weiss EP, Fontana L. Caloric restriction: powerful protection for the aging heart and vasculature. Am J Physiol Heart Circ Physiol 2011;301:H1205-19.

16. Semba RD, Najjar SS, Sun K, et al. Serum carboxymethyl-lysine, an advanced glycation end product, is associated with increased aortic pulse wave velocity in adults. Am J Hypertens 2009;22:74-9. 
17. Hofmann B, Adam AC, Jacobs K, et al. Advanced glycation end product associated skin autofluorescence: a mirror of vascular function? Exp Gerontol 2013;48:38-44.

18. Kubozono T, Miyata M, Ueyama K, et al. Acute and chronic effects of smoking on arterial stiffness. Circ J 2011;75:698-702.

19. Prasad A, Bekker P, Tsimikas S. Advanced glycation end products and diabetic cardiovascular disease. Cardiol Rev 2012;20:177-83.

20. Bruno RM, Penno G, Daniele G, et al. Type 2 diabetes mellitus worsens arterial stiffness in hypertensive patients through endothelial dysfunction. Diabetologia 2012;55:1847-55.

21. Lane MA, Black A, Handy A, et al. Caloric restriction in primates. Ann N Y Acad Sci 2001;928:287-95.

22. Lane MA, Mattison J, Ingram DK, et al. Caloric restriction and aging in primates: relevance to humans and possible CR mimetics. Microsc Res Tech 2002;59:335-8.

23. Roth GS, Ingram DK, Lane MA. Caloric restriction in primates and relevance to humans. Ann N Y Acad Sci 2001;928:305-15.

24. Heilbronn LK, Ravussin E. Calorie restriction extends life span-but which calories? PLoS Med 2005;2:e231.

25. Heilbronn LK, Ravussin E. Calorie restriction and aging: review of the literature and implications for studies in humans. Am J Clin Nutr 2003;78:361-9.

26. Heilbronn LK, de Jonge L, Frisard MI, et al. Effect of 6-month calorie restriction on biomarkers of longevity, metabolic adaptation, and oxidative stress in overweight individuals: a randomized controlled trial. JAMA 2006;295:1539-48.

27. Timmers S, Konings E, Bilet L, et al. Calorie restriction-like effects of 30days of resveratrol supplementation on energy metabolism and metabolic profile in obese humans. Cell Metab 2011;14:612-22.

28. Barzilai N, Banerjee $\mathrm{S}$, Hawkins $\mathrm{M}$, et al. Caloric restriction reverses hepatic insulin resistance in aging rats by decreasing visceral fat. $J$ Clin Invest 1998;101:1353-61.

29. Labinskyy N, Csiszar A, Veress G, et al. Vascular dysfunction in aging: potential effects of resveratrol, an anti-inflammatory phytoestrogen. Curr Med Chem 2006;13:989-96.

30. Botden IPG, Draijer R, Westerhof BE, et al. Red wine polyphenols do not lower peripheral or central blood pressure in high normal blood pressure and hypertension. Am J Hypertens 2012;25: 718-23.

31. Csiszar A, Labinskyy N, Podlutsky A, et al. Vasoprotective effects of resveratrol and SIRT1: attenuation of cigarette smoke-induced oxidative stress and proinflammatory phenotypic alterations. Am J Physiol Heart Circ Physiol 2008;294:H2721-35.

32. Donato AJ, Magerko KA, Lawson BR, et al. SIRT-1 and vascular endothelial dysfunction with ageing in mice and humans. J Physiol (Lond) 2011;589(Pt 18):4545-54.

33. Ota $\mathrm{H}$, Akishita $\mathrm{M}$, Eto $\mathrm{M}$, et al. Sirt1 modulates premature senescence-like phenotype in human endothelial cells. J Mol Cell Cardiol 2007;43:571-9. 